\title{
Head rotation, flexion, and extension alter endotracheal tube position in adults and children
}

\section{La rotation, la flexion et l'extension de la tête modifient le positionnement de la sonde endotrachéale chez l'adulte et l'enfant}

\author{
Jin-Tae Kim, MD, PhD · Hyun-Jung Kim, MD · Wonsik Ahn, MD, PhD · \\ Hee-Soo Kim, MD, PhD · Jae-Hyon Bahk, MD, PhD · Sang-Chul Lee, MD, PhD • \\ Chong-Sung Kim, MD, PhD $\cdot$ Seong-Deok Kim, MD, PhD
}

Received: 5 February 2009/Accepted: 15 July 2009/Published online: 29 July 2009

(C) Canadian Anesthesiologists' Society 2009

\begin{abstract}
Purpose The purpose of this study was to evaluate the effect of head rotation in adults and children on endotracheal tube (ETT) position and to confirm previous results regarding the influence of head flexion and extension on ETT position.

Methods After inducing anesthesia in 24 young adults and 22 children (aged 1-9 yr), ETTs were secured on the right corner of each of their mouths. Using a fiberoptic bronchoscope, the distance from the carina to the tip of the ETT was measured with each patient's head and neck placed in a neutral position, flexed, extended, rotated to the right, and rotated to the left.

Results In all patients, flexing the head resulted in the ETT moving towards the carina, and extension resulted in the tube being displaced in the opposite direction. In adults, head rotation to the right resulted in withdrawal of the ETT in all but one patient; displacement was $0.8 \pm 0.5 \mathrm{~cm}$ (mean $\pm S D)(P<0.001)$. Head rotation to the left resulted in the endotracheal tube being displaced in an unpredictable direction by $0.1 \pm 0.6 \mathrm{~cm}$. In children, head rotation to the right resulted in withdrawal of the ETT in all patients; displacement was $1.1 \pm 0.6 \mathrm{~cm}$
\end{abstract}

J.-T. Kim, MD, PhD · H.-J. Kim, MD · W. Ahn, MD, PhD .

H.-S. Kim, MD, PhD · J.-H. Bahk, MD, PhD ( $₫)$.

S.-C. Lee, MD, PhD - C.-S. Kim, MD, PhD .

S.-D. Kim, MD, PhD

Department of Anesthesiology and Pain Medicine, Seoul National University Hospital, Seoul National University College

of Medicine, \#28 Yongon-Dong, Jongno-Gu, Seoul 110-744,

Korea

e-mail: dream64992@hanmail.net
$(P<0.001)$. Head rotation to the left also resulted in partial withdrawal in all patients; displacement measured $0.6 \pm 0.4 \mathrm{~cm}(P<0.001)$.

Conclusions In adult patients under general anesthesia, head rotation towards the side of ETT fixation resulted in partial withdrawal of the tube tip away from the carina, whereas head rotation to the opposite side displaced the tube in an unpredictable manner. In children, head rotation to either side resulted in withdrawal of the ETT away from the carina.

\section{Résumé}

Objectif L'objectif de cette étude était d'évaluer l'effet de la rotation de la tête chez l'adulte et l'enfant sur le positionnement de la sonde endotrachéale et de confirmer les résultats précédents concernant l'influence de la flexion et de l'extension de la tête.

Méthode Après l'induction de l'anesthésie chez 24 jeunes adultes et 22 enfants (âgés de 1 à 9 ans), les sondes endotrachéales ont été fixées au coin droit de leurs bouches. A' l'aide d'un bronchoscope à fibre optique, la distance entre la carène et le bout de la sonde a été mesurée avec la tête et le cou de chaque patient positionnés de façon neutre, en flexion, en extension, tournés vers la droite et tournés vers la gauche.

Résultats Chez tous les patients, la flexion de la tête a provoqué le mouvement de la sonde endotrachéale vers la carène, et l'extension a provoqué le déplacement de la sonde dans la direction opposée. La rotation de la tête vers la droite a provoqué le retrait de la sonde chez tous les patients adultes, sauf un; le déplacement était de $0,8 \pm 0,5 \mathrm{~cm}$ (moyenne $\pm E T)(P<0,001)$. La rotation de 
la tête vers la gauche a provoqué un déplacement de la sonde de 0,1 0,6 cm dans une direction imprévisible. Chez les enfants, la rotation de la tête vers la droite a provoqué le retrait de la sonde chez tous les patients; le déplacement était de $1,1 \pm 0,6 \mathrm{~cm}(P<0,001)$. La rotation de la tête vers la gauche a également provoqué un retrait partiel de la sonde chez tous les patients; le déplacement était de 0,6 $\pm 0,4 \mathrm{~cm}(P<0,001)$.

Conclusion Chez les patients adultes sous anesthésie générale, la rotation de la tête vers le côté où la sonde était fixée a provoqué un retrait partiel de la pointe de la sonde par rapport à la carène, alors que la rotation dans la direction opposée a provoqué un déplacement de la sonde dans une direction imprévisible. Chez les enfants, la rotation de la tête de part et d'autre a provoqué un retrait de la sonde endotrachéale par rapport à la carène.

Head and neck movements can partially displace the ETT in a patient's intubated trachea. Displacements during neck flexion or extension have been well described. ${ }^{1-7}$ Flexion may cause carinal stimulation or endobronchial intubation by advancing the ETT, whereas extension can cause balloon-induced vocal cord damage or unintentional extubation by withdrawing the tube. However, previous studies examining the effect of head rotation on ETT position have generated inconsistent results. ${ }^{5-7}$ Furthermore, there are few studies examining the influence of head rotation on tube position in children.

Endotracheal tube displacement may depend on the direction of head rotation because the tube is fixed at one (usually right) corner of the mouth, and the head pivots on the vertebrae during rotation, not on the trachea. Therefore, we hypothesized that head rotation towards the side of fixation can partially withdraw the ETT tip, whereas rotation to the opposite side will either advance or withdraw the tube depending on the degree of rotation. Additionally, the influence of head rotation and its direction may be different in children because children have a larger occiput, more supple neck joints, and a smaller mouth than adults.

This study was performed to assess the effect of right and left head rotation on ETT displacement and to confirm previous results regarding the effects of neck flexion or extension on ETT position. The distance from the tip of the ETT to the carina was measured in adults and children using a fiberscopic technique.

\section{Methods}

The study protocol was approved by the Institutional Review Board of Seoul National University Hospital,
Seoul, Korea. Written informed consent was obtained from all adult patients and from the parents or legal guardians of the children. We screened 28 adult males aged $<35 \mathrm{yr}$ and taller than $165 \mathrm{~cm}$ and 33 children aged 1-10 yr. Exclusion criteria included patients with limited neck movement, neck pain, a history of neck surgery, no dentition, and refusal to be involved in the study. Three adults were excluded because of neck pain (1) and refusal (2). Six children were excluded because of a history of neck surgery (1) and refusal (5). Ultimately, 25 men and 25 children with American Society of Anesthesiologists (ASA) physical status 1 were enrolled in the study.

Standard monitors were applied in the operating room, including the electrocardiogram, pulse oximeter, and noninvasive blood pressure. Each adult's head was positioned on a $3 \mathrm{~cm}$ high headrest, and each child's head was positioned on a $1 \mathrm{~cm}$ high towel. After induction of anesthesia with thiopental $5 \mathrm{mg} \cdot \mathrm{kg}^{-1}$ and vecuronium $0.1 \mathrm{mg} \cdot \mathrm{kg}^{-1} i v$, the patients' lungs were ventilated with oxygen $4 \mathrm{~L} \cdot \mathrm{min}^{-1}$ and sevoflurane 4-6 vol.\% inspired concentration. After confirming muscle relaxation, each adult's trachea was intubated orally with a cuffed $7.5 \mathrm{~mm}$ internal diameter ETT (Hi-Lo $^{\mathrm{TM}}$, Mallinckrodt, Athlone, Ireland). An uncuffed ETT (Mallinckrodt, Athlone, Ireland) was used for the children, with the size selected for air leak at an inflation pressure of $15-35 \mathrm{~cm} \mathrm{H} \mathrm{H}_{2} \mathrm{O}$. Each adult's ETT was positioned so that the vocal cords were located between the two black marks on the tube shaft. The position was confirmed by a tactile sensation of the cuff in the suprasternal notch (cuff ballottement). In children, the ETT was advanced into the mainstem bronchus and withdrawn until equal breath sounds on both lung fields were audible; then the tube was withdrawn another 2-3 $\mathrm{cm}$ before being secured.

After the ETT was taped at the right corner of the patient's mouth, the insertion depth was checked at the upper incisor level. The distance from the ETT tip to the carina was measured using a fiberoptic bronchoscope (FOB) (outer diameter $3.7 \mathrm{~mm}$, Karl Storz, Tuttlingen, Germany; or outer diameter $3.1 \mathrm{~mm}$, Olympus Optical Co., Tokyo, Japan). Oxygen $100 \%$ was provided during the measurements, which were performed by a single investigator (J.-T. K.) at end-expiration. Distance from the ETT tip to the carina was measured as follows: ${ }^{8}$ (1) When the carina was just visualized at the tip of the FOB, a clip was placed on the FOB shaft at the level of the swivel elbow connector; (2) The FOB was then withdrawn until the tip of the ETT was at the end of the FOB; (3) Next, the distance between the clip and the uppermost level of the swivel connector was measured to the nearest $1 \mathrm{~mm}$ (Fig. 1). The measurement was performed in random order with the patient's head and neck placed as follows: in a neutral position, rotated to the right, rotated to the left, fully flexed, or fully extended. 


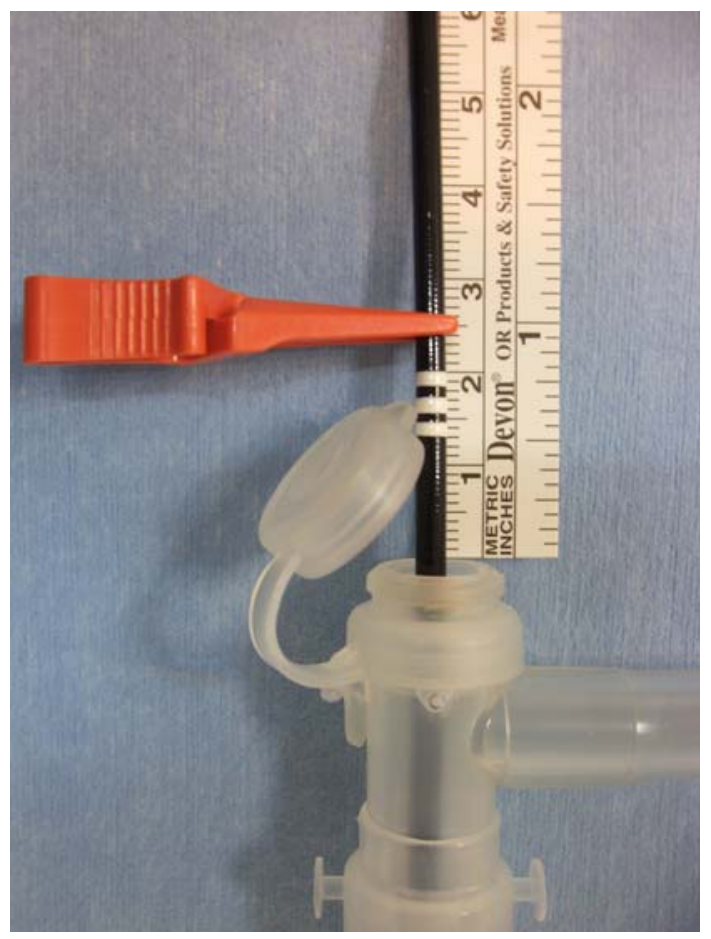

Fig. 1 Method of measuring the distance from the carina to the tip of the endotracheal tube. The tip of the bronchoscope was first held at the carina with a clip applied at the connector. Then the bronchoscope was slowly withdrawn to the tip of the endotracheal tube. The clip-toconnector distance was considered equal to the distance between the endotracheal tube tip and the carina

Data are expressed as mean \pm SD (range). A clinically significant displacement was defined as movement of the ETT $>1 \mathrm{~cm}$ in either direction. This minimal clinically important difference was selected on the basis that the anterior branch of the recurrent laryngeal nerve in adults is most vulnerable $1 \mathrm{~cm}$ below the vocal cords, ${ }^{9}$ and the distance from the proximal margin of the cuff to the distal black line on the ETT is approximately $2 \mathrm{~cm}$. Although cuffed tubes were not used in children, the $1 \mathrm{~cm}$ definition was maintained for consistency, despite the narrower safety margin of tube position.

The changes of ETT tip position from the neutral position were analyzed by paired Student's $t$ tests. Each $P$ value for the four tests was adjusted by dividing the critical $P$-value of 0.05 by the number of tests.

\section{Results}

One adult patient was excluded from the study because of undetected previous neck surgery, and data from three children were incomplete due either to transient oxygen desaturation or lack of time to complete the study. Therefore, 24 adults and 22 children were studied (Table 1). In all patients, the Cormack and Lehane laryngeal view
Table 1 Patient characteristics

\begin{tabular}{lll}
\hline & Adults $(n=24)$ & Children $(n=22)$ \\
\hline Age (year) & $22 \pm 3(20-32)$ & $4.6 \pm 2.7(1.1-9.0)$ \\
Weight $(\mathrm{kg})$ & $73 \pm 11(59-100)$ & $19.4 \pm 7.4(10.2-36.9)$ \\
Height $(\mathrm{cm})$ & $175 \pm 4(168-185)$ & $106 \pm 18(76-132)$ \\
Sex $(\mathrm{M} / \mathrm{F})$ & $24 / 0$ & $14 / 8$ \\
\hline
\end{tabular}

Data are presented as mean \pm SD (range)

grade $^{10}$ under direct laryngoscopy was either 1 or 2 . In adults, the insertion depth at the upper incisor was $22.8 \pm 0.6(21.5-24.0) \mathrm{cm}$, and in children, it was $14.5 \pm$ $1.9(12.0-18.0) \mathrm{cm}$.

The extent of individual displacement of the ETT tip from the neutral position in adults is shown in Fig. 2. The tube tip moved toward the carina by $1.3 \pm 0.6(0.5-$ $2.5) \mathrm{cm}$ with neck flexion $(P<0.001)$, and away from the carina by $1.7 \pm 0.8(0.4-3.1) \mathrm{cm}$ with neck extension $(P<0.001)$. With the exception of one patient, head rotation to the right withdrew the tube; displacement was $0.8 \pm 0.5(-0.1$ to 1.7$) \mathrm{cm}(P<0.001)$. Rotation to the left displaced the ETT in an unpredictable manner (no movement in three patients, advancement in 10 patients, and withdrawal in 11 patients); mean movement was $0.1 \pm 0.6(-1.0$ to 0.9$) \mathrm{cm}(P=0.56)$.

In adults, ETT displacements $>1 \mathrm{~cm}$ in adults occurred in $71 \%$ of patients during flexion and $79 \%$ of patients during extension. During head rotation to the right, clinically significant $(>1 \mathrm{~cm})$ ETT withdrawal occurred in 33\% of patients, and during head rotation to the left, withdrawal occurred in $4 \%$ of patients.

For children, individual displacements of the ETT tip from the neutral position are shown in Fig. 3. The tip moved towards the carina by $1.0 \pm 0.5(0.1-2.0) \mathrm{cm}$ with neck flexion $(P<0.001)$ and away from the carina by $1.8 \pm 0.8$ $(0.7-3.8) \mathrm{cm}$ with neck extension $(P<0.001)$. Head rotation either to the right or to the left moved the ETT away from the carina in all patients. During head rotation to the right, the ETT tip withdrew by $1.1 \pm 0.6(0.2-2.5) \mathrm{cm}$ $(P<0.001)$, and during head rotation to the left, the tip withdrew by $0.6 \pm 0.4(0.1-1.5) \mathrm{cm}(P<0.001)$.

In children, clinically significant ETT displacement $(>1 \mathrm{~cm})$ occurred in $50 \%$ of patients during flexion and in $90 \%$ of patients during neck extension. Withdrawal $>1 \mathrm{~cm}$ occurred in $46 \%$ of patients during head rotation toward the ETT fixation side and in $23 \%$ of patients during head rotation to the opposite side.

\section{Discussion}

In adults, head rotation towards the side of ETT fixation displaces the ETT tip away from the carina, while rotation 
Fig. 2 In adults, individual displacements of the endotracheal tube tip from the neutral position. In these boxand-whisker plots, the box boundaries display the first and third quartiles, and the whiskers represent the minimum and maximum values. The horizontal line within the box represents the mean value. $n=24, * P<0.001$ vs the neutral position
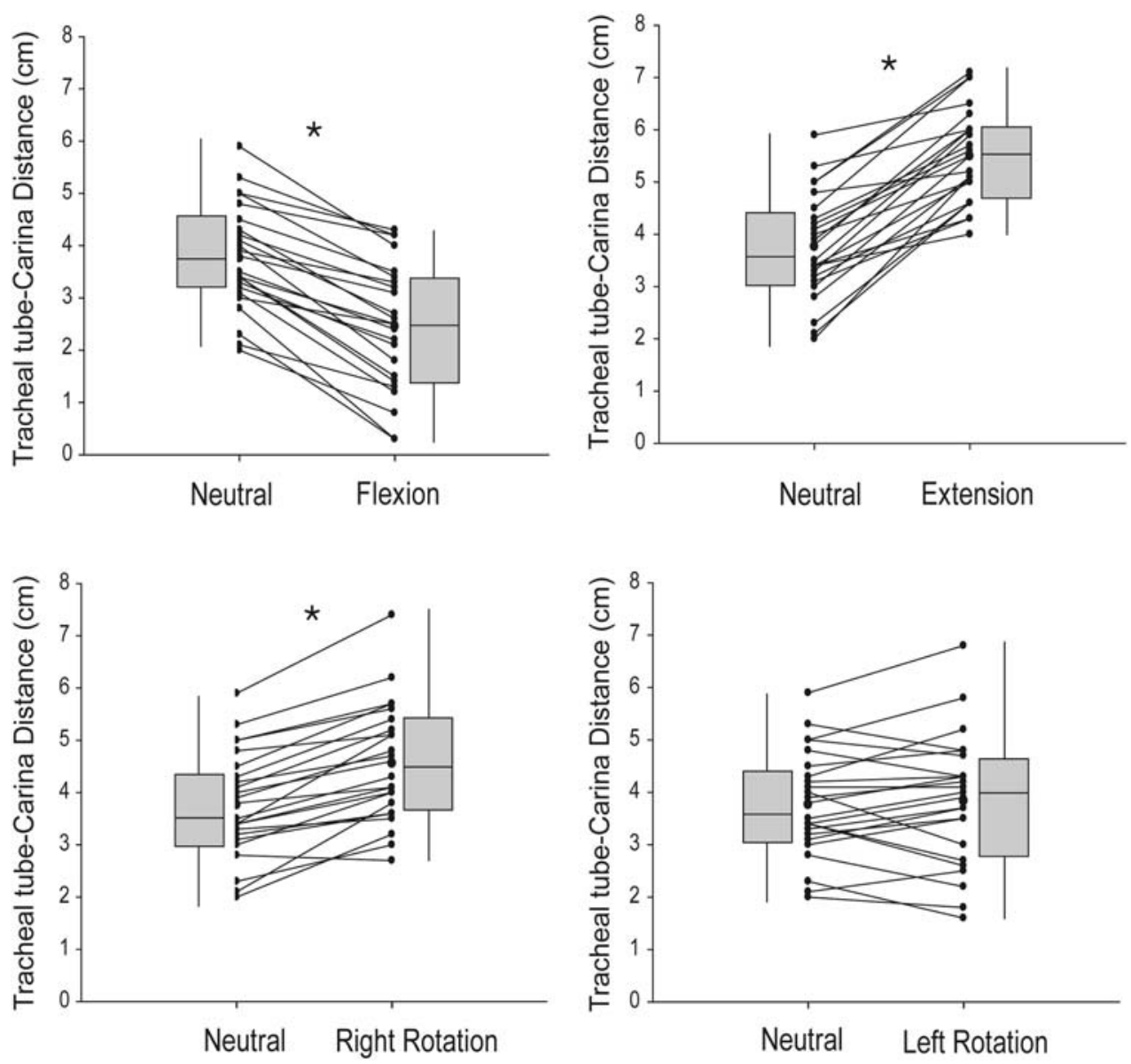

to the opposite side displaces the tip in an unpredictable manner. If the head's axis of rotation were the trachea, the movement of the ETT tip would not have been influenced by the direction of head rotation. However, the head's axis of rotation is the cervical vertebral column, and the trachea is located anterior to this column. Therefore, head rotation towards the tube fixation side withdraws the ETT tip when the fixation site is at one corner of the mouth. The movement of the tube during head rotation to the non-fixation side may depend on the degree of rotation and the size of the patient's mouth.

In contrast to adults, a child's head rotation to either side withdraws the ETT tip from the carina. The reason for this discrepancy between adults and children may be that the occipital size relative to the cranium is greater in children than in adults. In addition, the results might be affected by a smaller mouth, a tube fixed closer to the midline, a more supple neck joint, and a greater degree of rotation. We also noticed in children that withdrawal was greater with rotation towards the fixation side. Although a component of neck extension may be added when the head is rotated, the basic mechanism of ETT movement during head rotation may be similar to that in adults. As a result, the tube displacement was greater during rotation to the fixation side than to the non-fixation side.

According to a previous study in adults, head rotation is not associated with any consistent inward or outward movement. ${ }^{5}$ However, there was no standardization of patients' characteristics, such as age, dentition, height, and weight. Furthermore, the presence of an oral airway was not specified, which may be associated with restriction of ETT movement. Every effort was made in our study to eliminate these confounding factors by confining gender, age, and height, by applying consistent head positions without an oral airway, by fixing the ETT tightly at the mouth, and by confirming the smooth curvature of the tube by palpation in the oral cavity.

In their radiographic study in pediatric patients, Olufolabi et al. concluded that head rotation either to the right or to the left did not result in movement of the ETT tip in any consistent pattern. ${ }^{7}$ However, closer inspection of their results reveals that head rotation to the right withdraws the tip of the tube away from the carina to a greater degree than rotation to the left. In that study, it was concluded that even flexion of the neck did not displace the ETT significantly. 
Fig. 3 In children, individual displacements of the endotracheal tube tip from the neutral position. In these boxand-whisker plots, the box boundaries display the first and third quartiles, and the whiskers represent the minimum and maximum values. The horizontal line within the box represents the mean value. The circle is an outlier. $n=22$,

$* P<0.001$ vs the neutral position
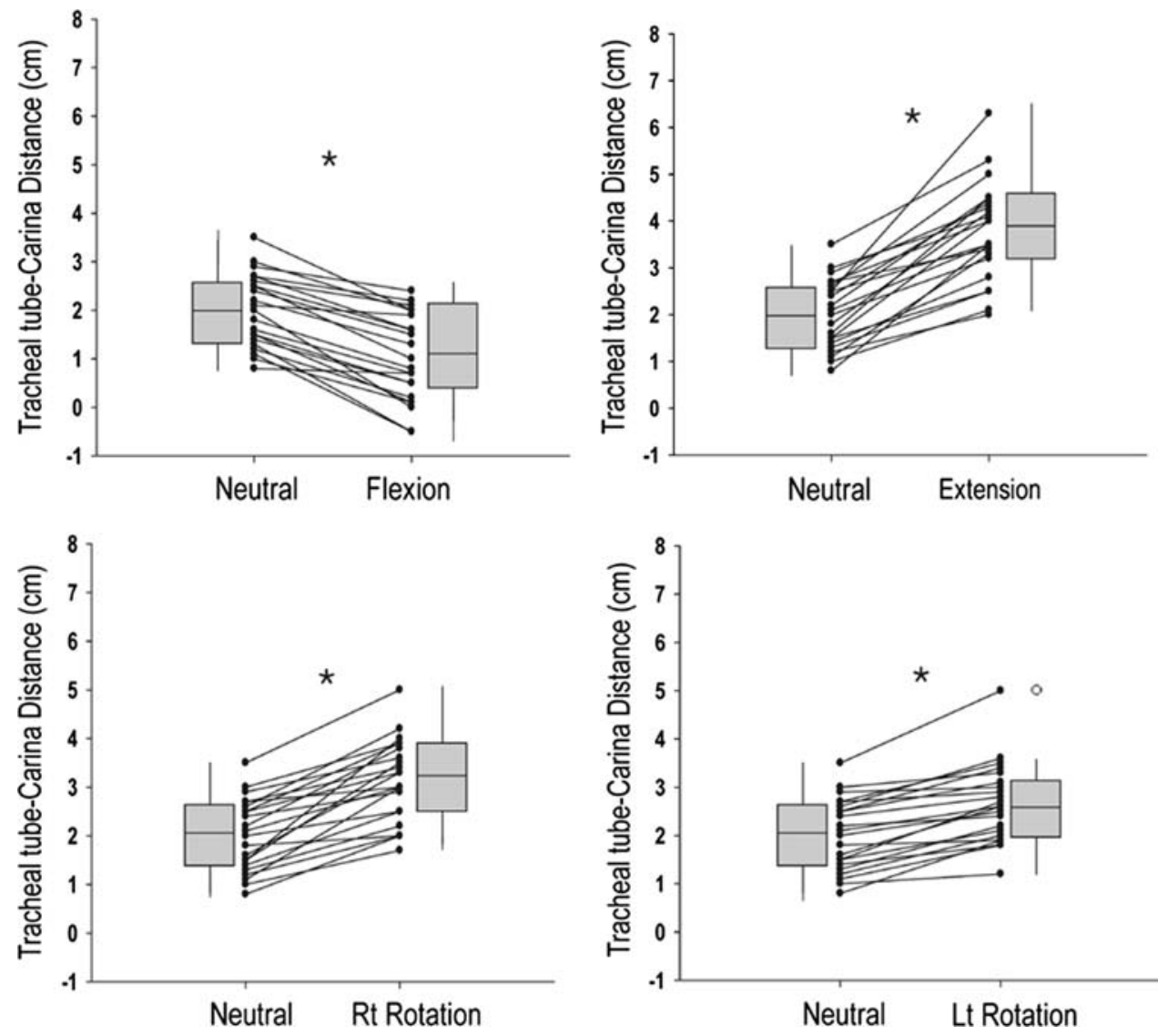

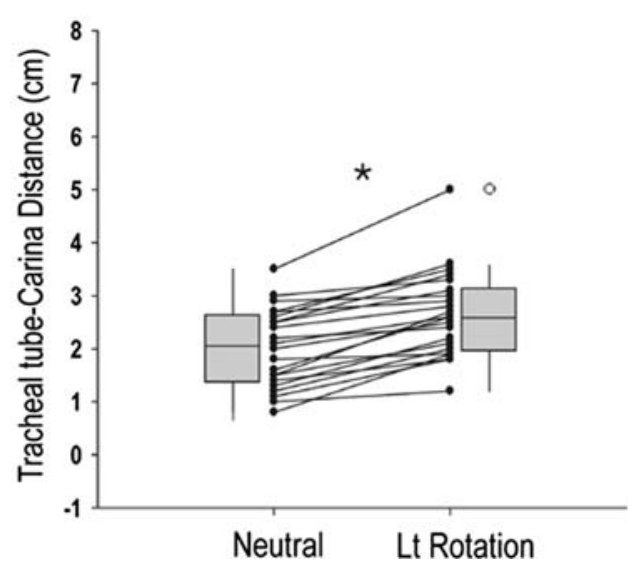

Therefore, there is a possibility that the tube movement was underestimated.

In their adult study, Hartrey and Kestin reported that head rotation to the right moved the ETT tip a mean of $2 \mathrm{~mm}$ away from the carina, while rotation to the left moved it a mean of $4 \mathrm{~mm}$ towards the carina. ${ }^{6}$ In our study, head rotation to the fixation side moved the ETT tip by a mean of $7-8 \mathrm{~mm}$ away from the carina, while rotation to the non-fixation side moved the tip in an unpredictable manner. Since our subjects were young males, the degree of rotation might have been greater than in the other studies, and this may be regarded as one limitation of our study.

Movement during head rotation was less than that observed during neck extension or flexion. Significant withdrawal $(>1 \mathrm{~cm})$ occurred in $79 \%$ of adults and $90 \%$ of children during neck extension. Neck flexion significantly displaced the tube in $71 \%$ of adults and $50 \%$ of children. We found that head rotation to the fixation side produced significant displacement in $33 \%$ of adults and $46 \%$ of children, while head rotation to the opposite side displaced the ETT significantly in $4 \%$ of adults and $23 \%$ of children. Therefore, special care is warranted to maintain desired ETT position, especially in children during head rotation.
This study has several limitations. Data collection was performed by unblinded observers, which may have introduced a possible source of bias. In addition, we collected the data with ETT fixation on the right side only, which is the usual fixation side. However, as normal airway anatomy is symmetrical, it is unlikely that any difference between right-sided and left-sided ETT fixation would have been of clinical importance. Finally, ETT movement could be proportionately greater in infants, so further studies in this age group are warranted.

In conclusion, in both adults and children under general endotracheal anesthesia, head rotation towards the ETT fixation side can withdraw the ETT tip away from the carina. Head rotation to the non-fixation side can withdraw the ETT in children, but not in adults. Because age and direction of rotation influence the displacement of the ETT tip during head rotation, anesthesiologists should carefully consider the direction of head rotation and the patient's age when positioning the head and neck of patients with orally intubated tracheae.

Disclaimers None.

Financial support None.

Conflicts of interest None declared. 


\section{References}

1. Conrardy PA, Goodman LR, Lainge F, Singer MM. Alteration of endotracheal tube position. Flexion and extension of the neck. Crit Care Med 1976; 4: 7-12.

2. Goodman LR, Conrardy PA, Laing F, Singer MM. Radiographic evaluation of endotracheal tube position. Am J Roentgenol 1976; 127: 433-4.

3. Sugiyama K, Yokoyama K. Displacement of the endotracheal tube caused by change of head position in pediatric anesthesia: evaluation by fiberoptic bronchoscopy. Anesth Analg 1996; 82: 251-3.

4. Rost JR, Frush DP, Auten RL. Effect of neck position on endotracheal tube location in low birth weight infants. Pediatr Pulmonol 1999; 27: 199-202.

5. Yap SJ, Morris RW, Pybus DA. Alterations in endotracheal tube position during general anaesthesia. Anaesth Intens Care 1994; 22: $586-8$.
6. Hartrey R, Kestin IG. Movement of oral and nasal tracheal tubes as a result of changes in head and neck position. Anaesthesia 1995; 50: 682-7.

7. Olufolabi AJ, Charlton GA, Spargo PM. Effect of head posture on tracheal tube position in children. Anaesthesia 2004; 59: 1069-72.

8. Weiss M, Gerber AC, Dullenkopf A. Appropriate placement of intubation depth marks in a new cuffed paediatric tracheal tube. Br J Anaesth 2005; 94: 80-7.

9. Cavo JW Jr. True vocal cord paralysis following intubation. Laryngoscope 1985; 95: 1352-9.

10. Cormack RS, Lehane J. Difficult tracheal intubation in obstetrics. Anaesthesia 1984; 39: 1105-11. 